Historic, Archive Document

Do not assume content reflects current scientific knowledge, policies, or practices. 



\section{Strawberries for Bigger Profits}

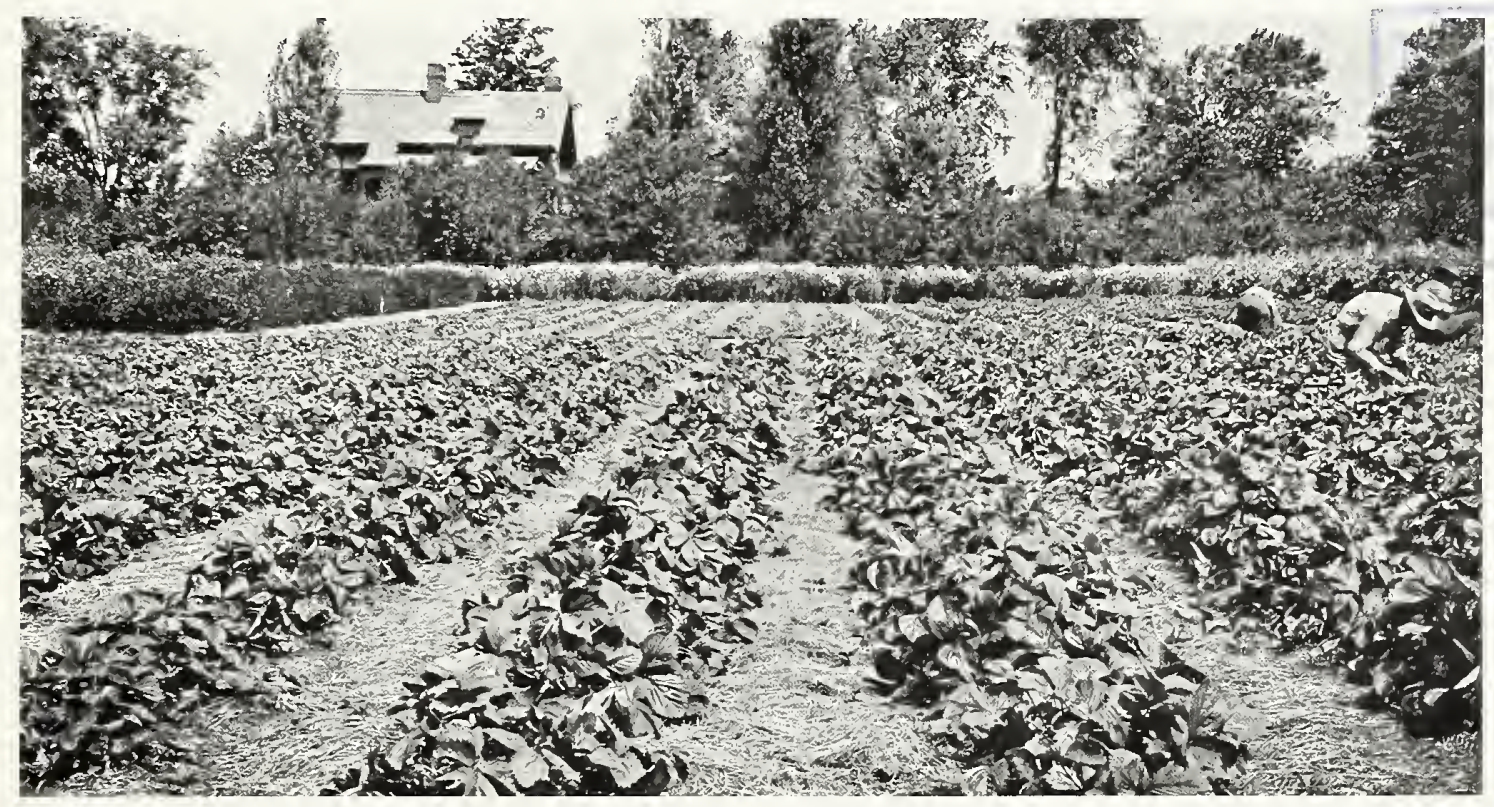

Strawberries give bigger profits and quicker returns than anything else you can grow. An acre field like this will soon help lift a mortgage or buy an automobile. Plant a foot apart in the rows, and the rows three and one-half feet apart, requiring 12,450 plants to the acre. 


\section{General Information to Our Salesmen}

Sell Strawberry plants for SPRING DELIVERY ONLY. Write the orders on the special order blanks furnished for that purpose. Years of experience with strawberry plants have convinced us that it is a loss of time and money for customers to set plants in the fall, especially for commercial purposes. They should be planted in the early spring and allowed to multiply the first summer if a large profitable crop is desired.

WE PACK IN HEAVY CORRUGATED BOXES OF OUR OWN DESIGN. These boxes have holes punched in them to allow proper ventilation. We pack the plants in moss and guarantee delivery to customer in first class condition. Plants are shipped by Parcel Post or Express, C. O. D. direct to customers who pay the amount of their order to the Postmaster, Rural Route carrier or express agent on receipt of the plants. This enables us to deliver plants to customer within 24 to 48 hours after being packed. Familiarize your customers thoroughly with the terms and conditions on which strawberry plants are sold.

WE PREPAY ALL TRANSPORTATION CHARGES.

Never sell less than 25 plants of a variety and always in multiples of 25 as we cannot stop to break bunches when filling orders.

SUITABLE DISTANCES FOR PLANTING. In beds, set II/2 by $I^{I} / 2$ feet apart. For commercial use, set one foot apart in the row and the rows $3 \frac{1}{2}$ feet apart, requiring 12,450 plants to the acre.

WE SHIP NOTHING BUT STRONG, VIGOROUS, YOUNG PLANTS.

\section{Culture of Strawberries}

The ground should be prepared the same as for other crops; if not already rich, make it so by manuring. In the early winter, when the ground is frozen, cover the whole with long straw, which should be partially removed from the row in the spring, but enough allowed to remain on the ground as mulch to keep the berries clean the following summer.

Every home builder with a back yard or garden who fails to have delicious, healthgiving strawberries of his own growing, misses the chance of great things for little money. Whether you are living in Maine, or California, or Florida, or Missouri, or any other state in the Union, you can and should grow all of the strawberries that you can use-the cost and effort is so little as not to be worth considering.

When planted in large quantities for commercial use strawberries are very profitable to the grower and bring about the first cash of the season, and at a time of the year when there is little around a farm that is bringing in ready money. By all means plant at least a small strawberry patch. 


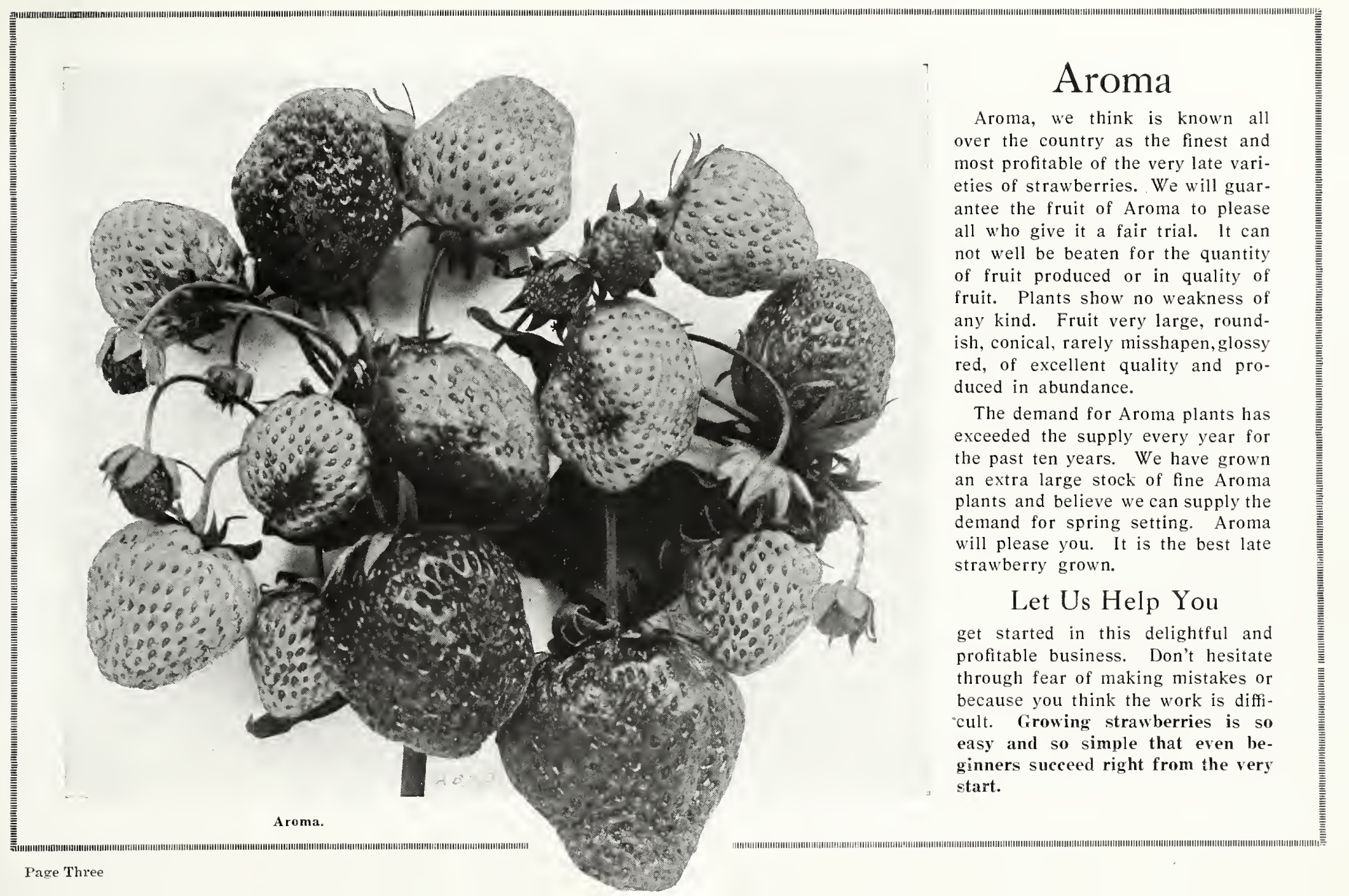




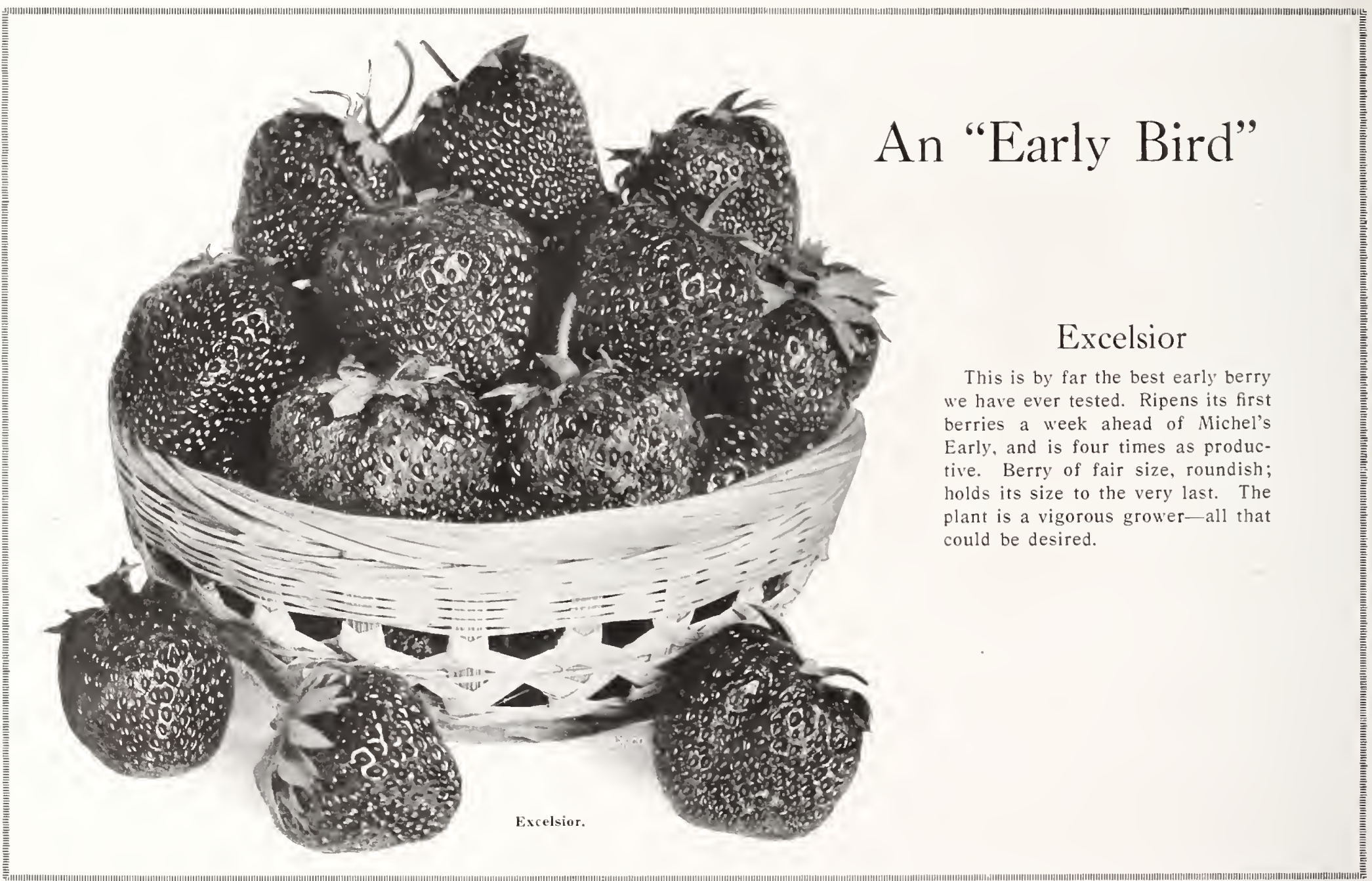




\section{This Reliable Variety Comes About a Week Later}

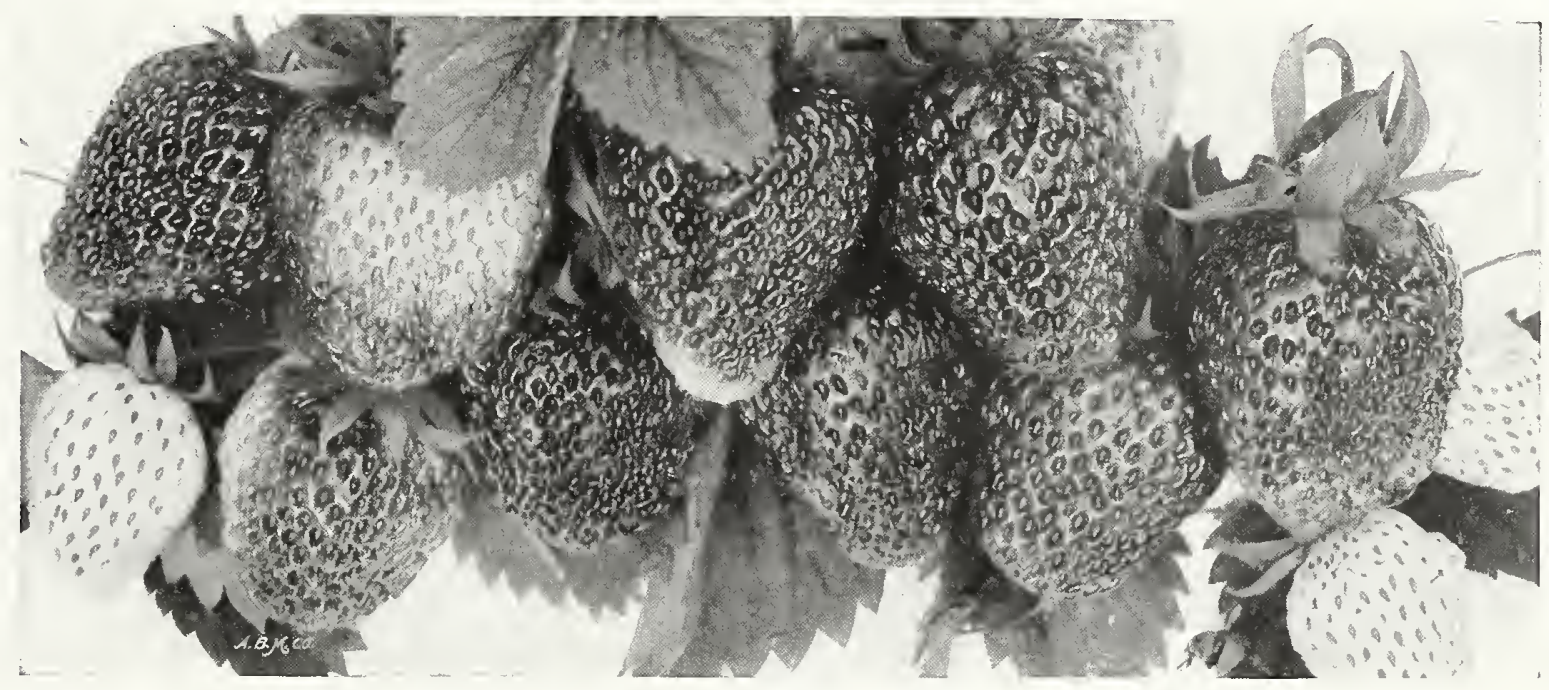

\section{Senator Dunlap}

This is the leading strawberry throughout the United States. We sell more Senator Dunlap plants than any other variety, and the demand for this variety has steadily increased every year since its introduction. It does well everywhere and produces enormous crops of fine fruit regularly.

Senator Dunlap is of the Warfield type, has a perfect blossom, is hardy, productive, a splendid keeper and able to hold its own under any "rough and tumble" methods of culture to which it is likely to be subjected. Senator Dunlap is a very heavy bearer of good size, evenly shaped, fruit of a very beautiful cark red color and its flavor is delicious. For canning it is fine, making a rich. red syrup. It is a first class shipper, and retains its brightness long after being picked. It always looks well on the market and sells quickly at top prices. 


\section{For Mid-Season Plant Klondyke}

This Splendid Berry Commands Hişh Prices

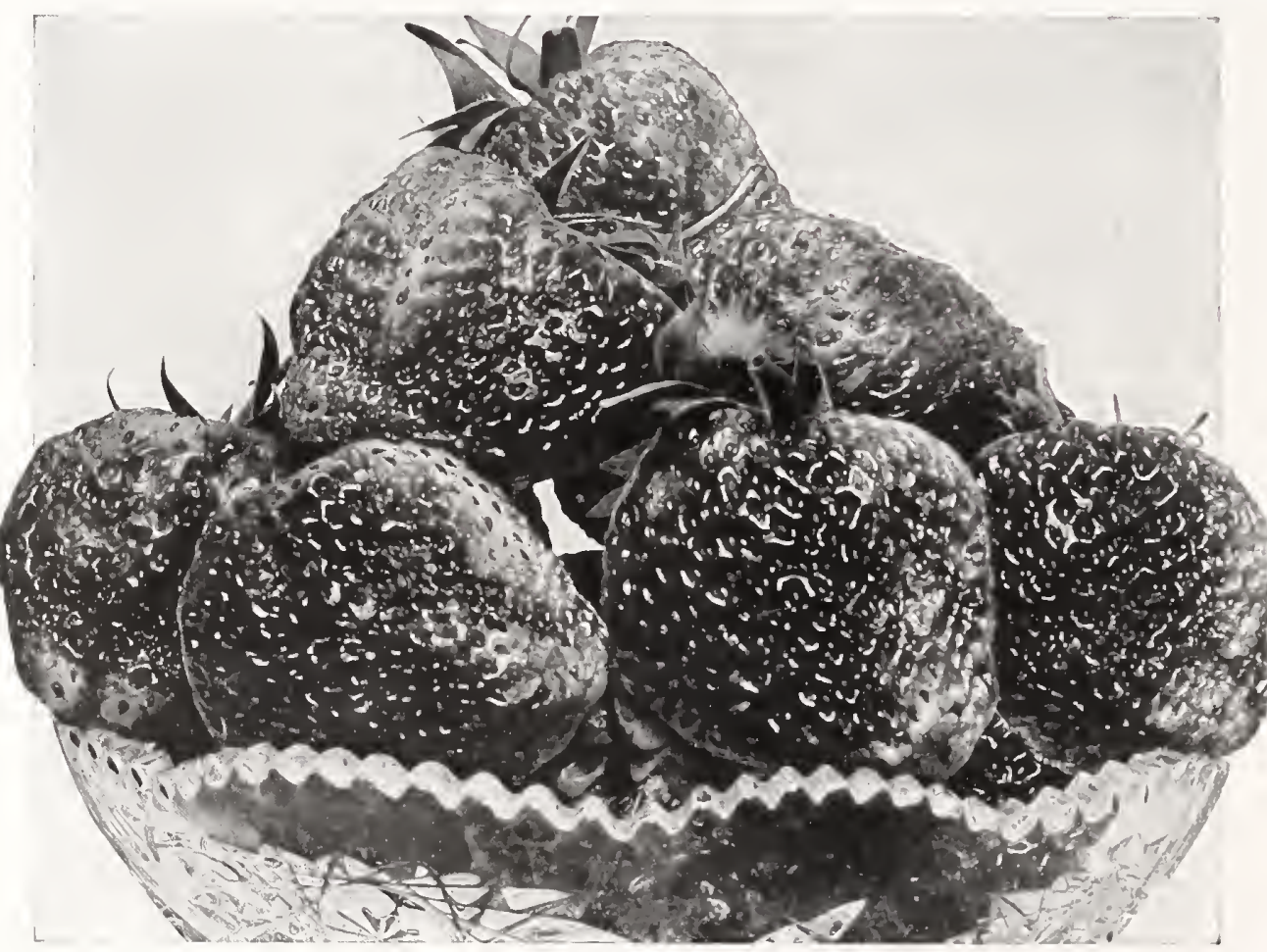

Klondyke.

\section{Klondyke}

The Klondyke is the most popular of all Southern varieties. Berries are good sized, regularly shaped and are very attractive, bringing top prices on any market. Extra valuable for long distance shipping. We have so much call for this variety that we planted a large stock of Klondyke last spring and now have a fine lot of plants.

\section{A Strawberry Garden}

55 feet square will accommodate 200 plants when set $2 \frac{\mathrm{I}}{2}$ feet part each way.

Our Special Garden Collection consists of 200 plants, the proper amount required for the average family. This will give you enough fruit for your table during the strawberry season and supply you with enough fruit to preserve for future use.

This selection, which should be found in every garden consists of the following:

50 Excelsior. Extra early.

50 Senator Dunlap. Ripening about a week late.

50 Kilondyke. Mid-season.

50 Aroma. Late.

Don't pass up this collection. The price is within reach of everyone. 
One of the Good Late
Sorts

Gandy

This is one of the leading late varieties with fruit growers all over the country. The plant is a strong grower, fruit is large and firm, but does not yield as heavy as some; requires strong soil and fertilizers to do its best. It is very late and a big showy berry. Gandy is always quoted at the highest price in every market. It is the finest looking fruit and sells quickly at top prices.

You will not make a mistake if you plant some Gandy for late fancy berries. We have a fine stock of heavy rooted plants.

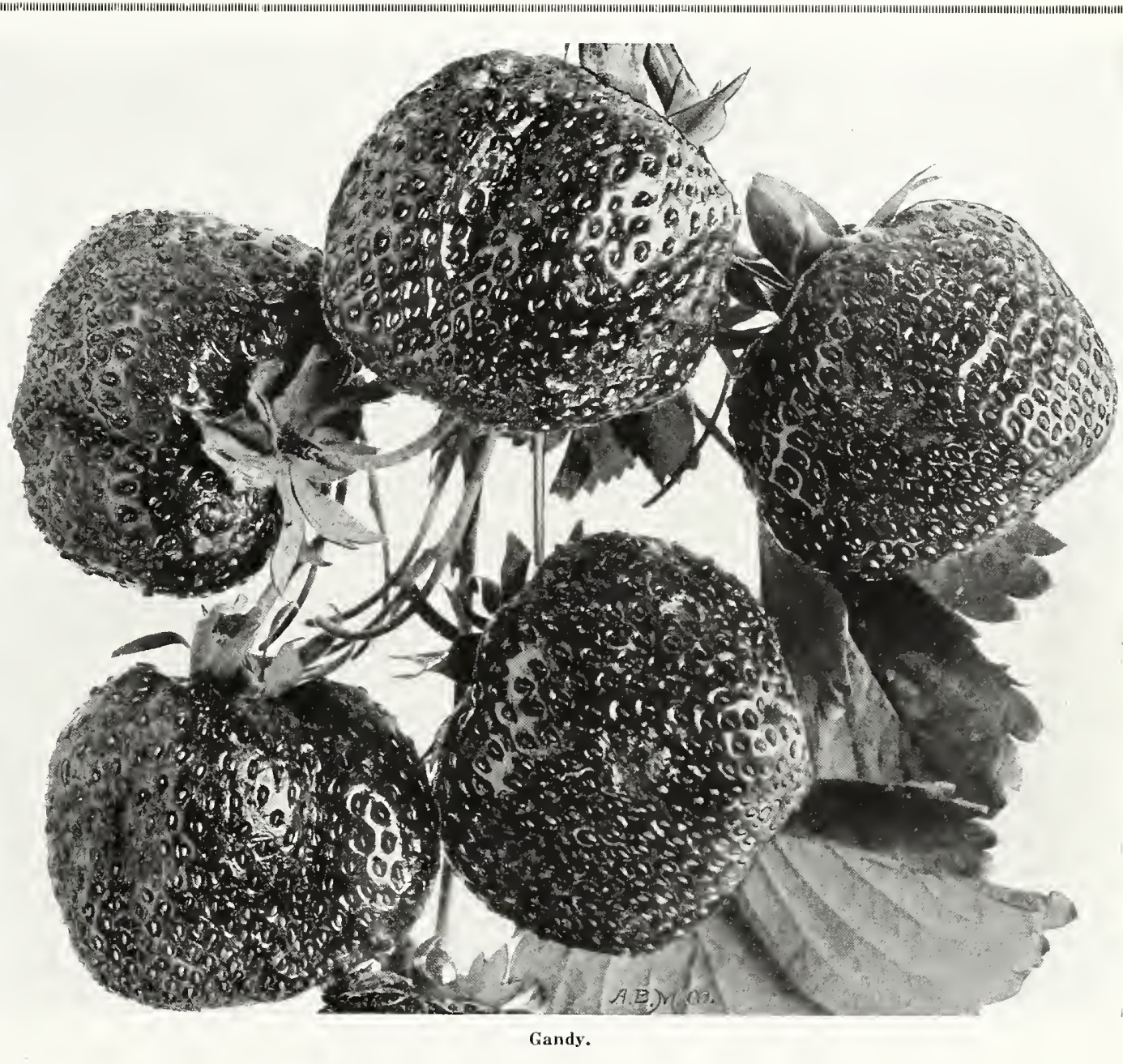




\section{One of the Best}

\section{Glen Mary}

Large and choice, very handsome, and of fine flavor; vigorous and productive. It is as large as the Sharpless and of superior quality. In productiveness it far surpasses the Crescent, not in number of berries, but quarts of berries. Many growers consider this the most profitable of strawberries. Glen Mary is not only an extra good berry for fancy market, but a real money maker for any market. We believe one can pick as many quarts of good berries from Glen Mary as from any other variety and they will sell quickly at a good figure. We recomniend this variety to our customers with perfect confidence that it will please them.

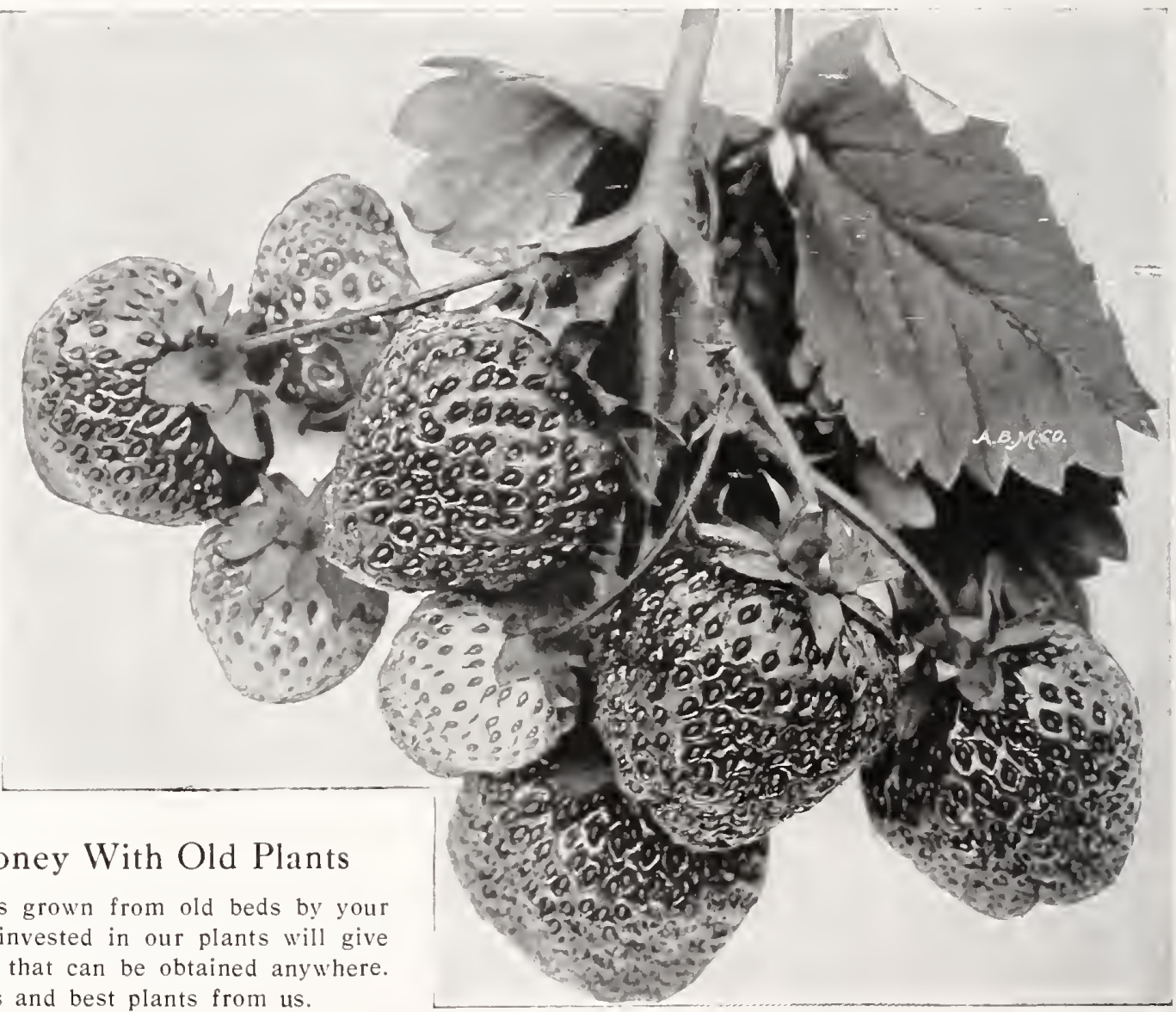

Glen Mary.

\section{Don't Waste Time and Money With Old Plants}

because they are cheap, or with plants grown from old beds by your friends or neighbors. A few dollars' invested in our plants will give you the best, most productive varieties that can be obtained anywhere. Start right by getting the best varieties and best plants from us. 


\section{Everbearing Strawberries}

What lingering doubts may have been felt as to the practical value of this new race of strawberries are rapidly vanishing in the light of experience. There is now scarcely a discordant note in the general praise of their qualities for the home garden, and the developments of the present season indicate a greater va'ue for the market garden than had before seemed probable. They have been on trial over a wide territory for about six years and the following points clearly demonstrated.

1st. Extreme health of foliage. Nothing approaching it has been exhibited by any of the old line varieties. This is especially true of the Progressive which scarcely shows a rusted leaf while

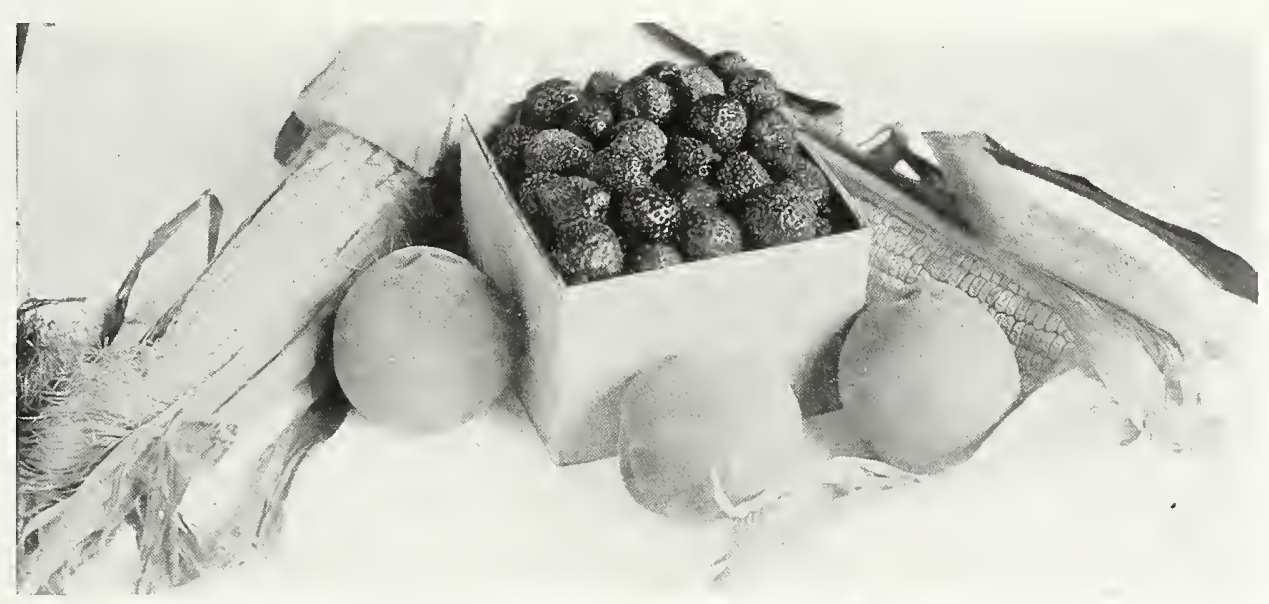

Superb Everbearing Strawberries, Peaches and Corn, Picked in October. other varieties planted near it may be badly affected. All strawberry growers know that healthy foliage means capacity for heavy fruiting.

2nd. Extreme hardiness of plant. Even the plants that by accident may have been left uncovered along the rows generally come through the winter in good condition.

3rd. The plants produce a good crop the season they are set. The planter does not have to wait a year for returns; really only a few weeks. This enlarges the opportunity of tenant farmers, and those who must have fruit at once.

4th. They are the only early strawberry. Affords a good picking a week before the first early varieties of the old kind.

5 th. The crop they bear in June compares well with the old varieties, especially in unfavorable seasons where frost or heat cuts short the main crop.

6th. The quality is simply exquisite, far sweeter than the standard kinds that we have been growing for twenty years. In this matter the Progressive is decidedly at the head.

7 th. In addition to this list of qualifications the Progressive has proved a first class plant maker. A great improvement over the everbearers first sent out. Not too much so for good fruiting but making what would be called ideal matted rows. 


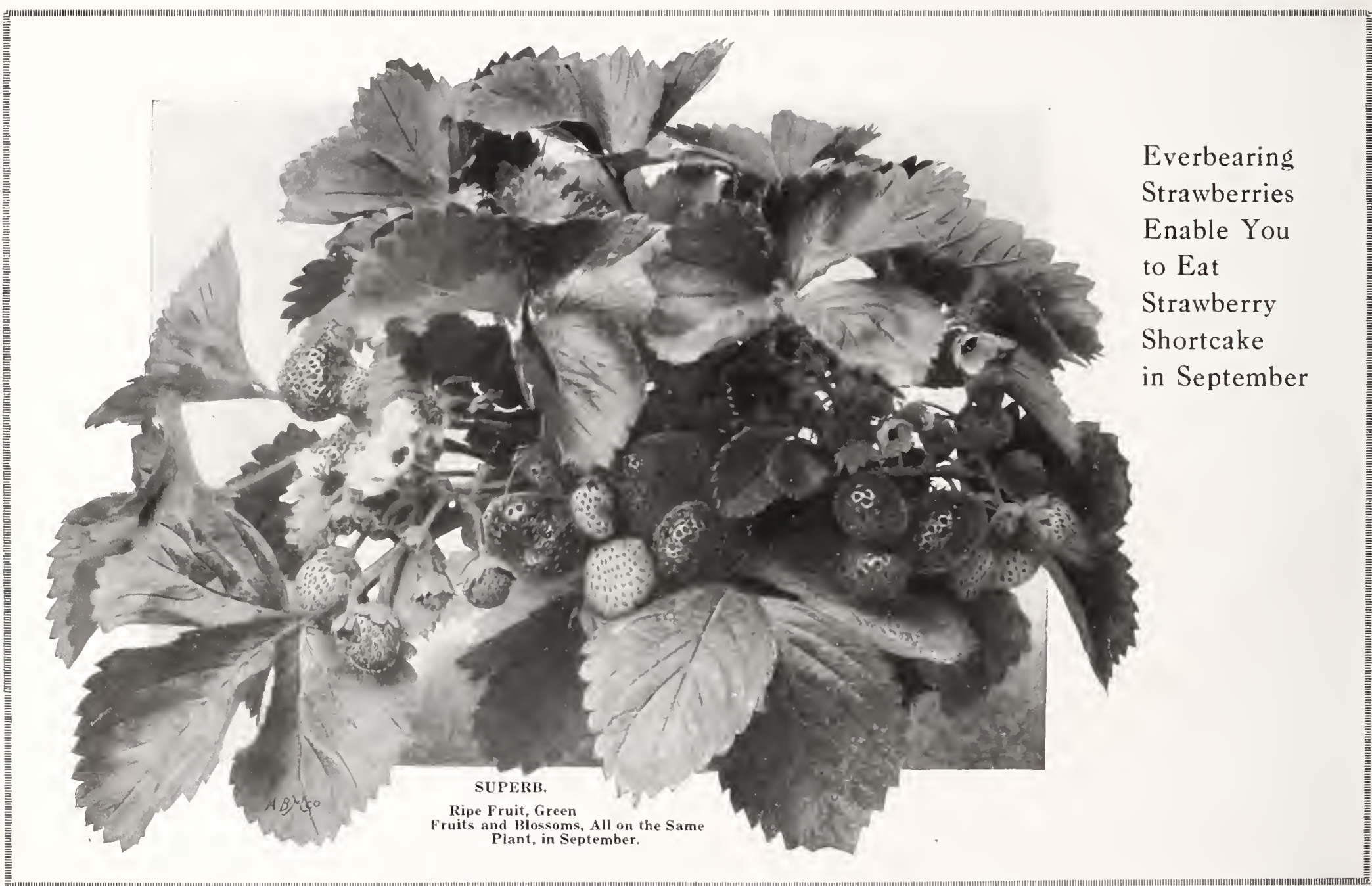


Superb and Progressive Are the Two Best Everbearing Varieties
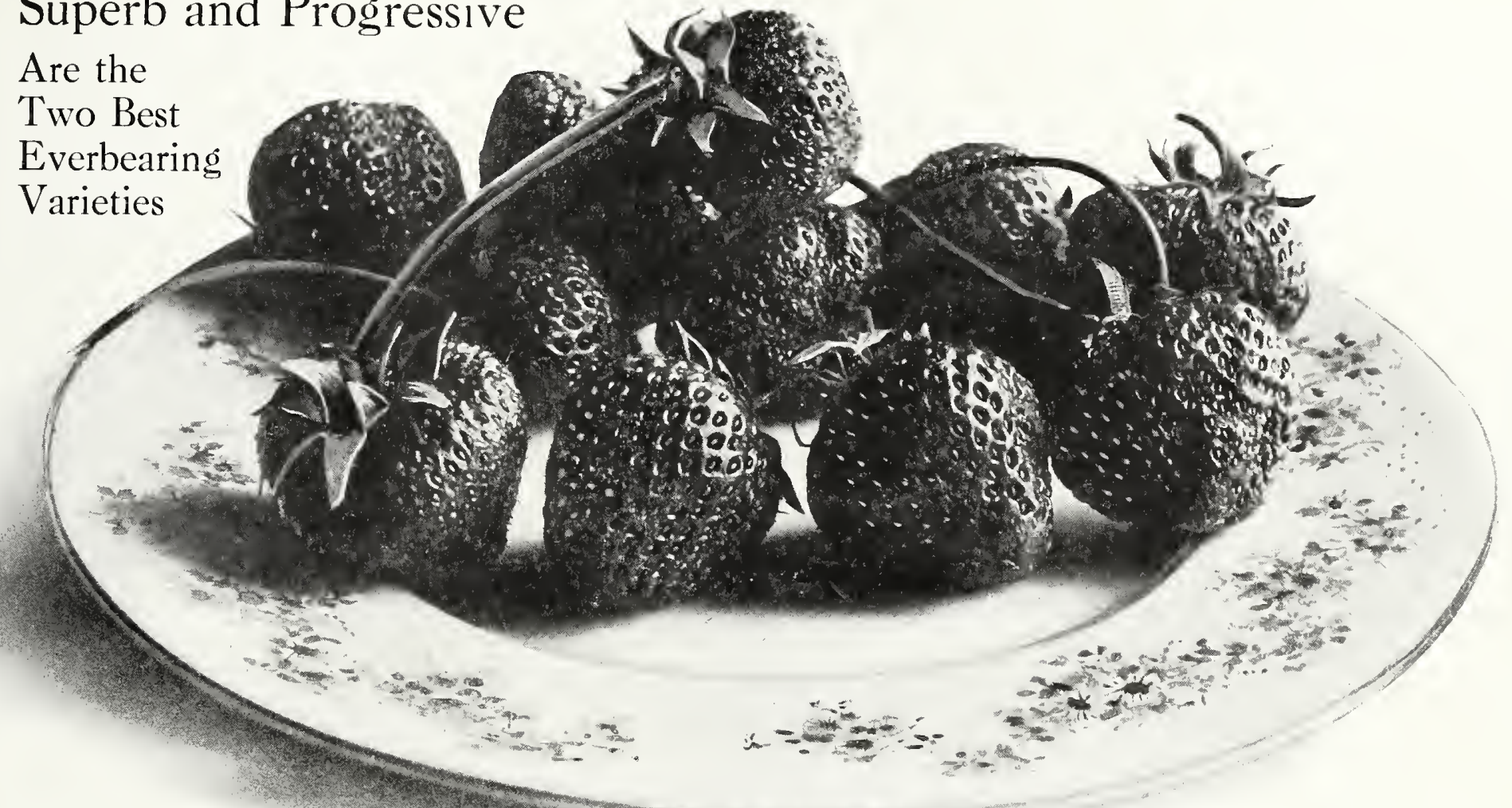
THIS SUPPLEMENT TO OUR PLATE BOOK contains a list of the best varieties of strawberries, both for home consumption and commercial use. Sell these varieties first, last and all the time. Sell the other varieties only when you cannot sell these, or, when customers specially want other sorts.

WE ARE EXCLUSIVELY IN THE NURSERY BUSINESS and do not produce any fruit for market. Our orders are filled from fields that are grown for PLANTS ONLY; plants that are strong, vigorous and possess the greatest possib!e vitality.

PLANTS THAT HAVE BEEN WEAKENED BY BEARING FRUIT ARE NOT WORTH SETTING.

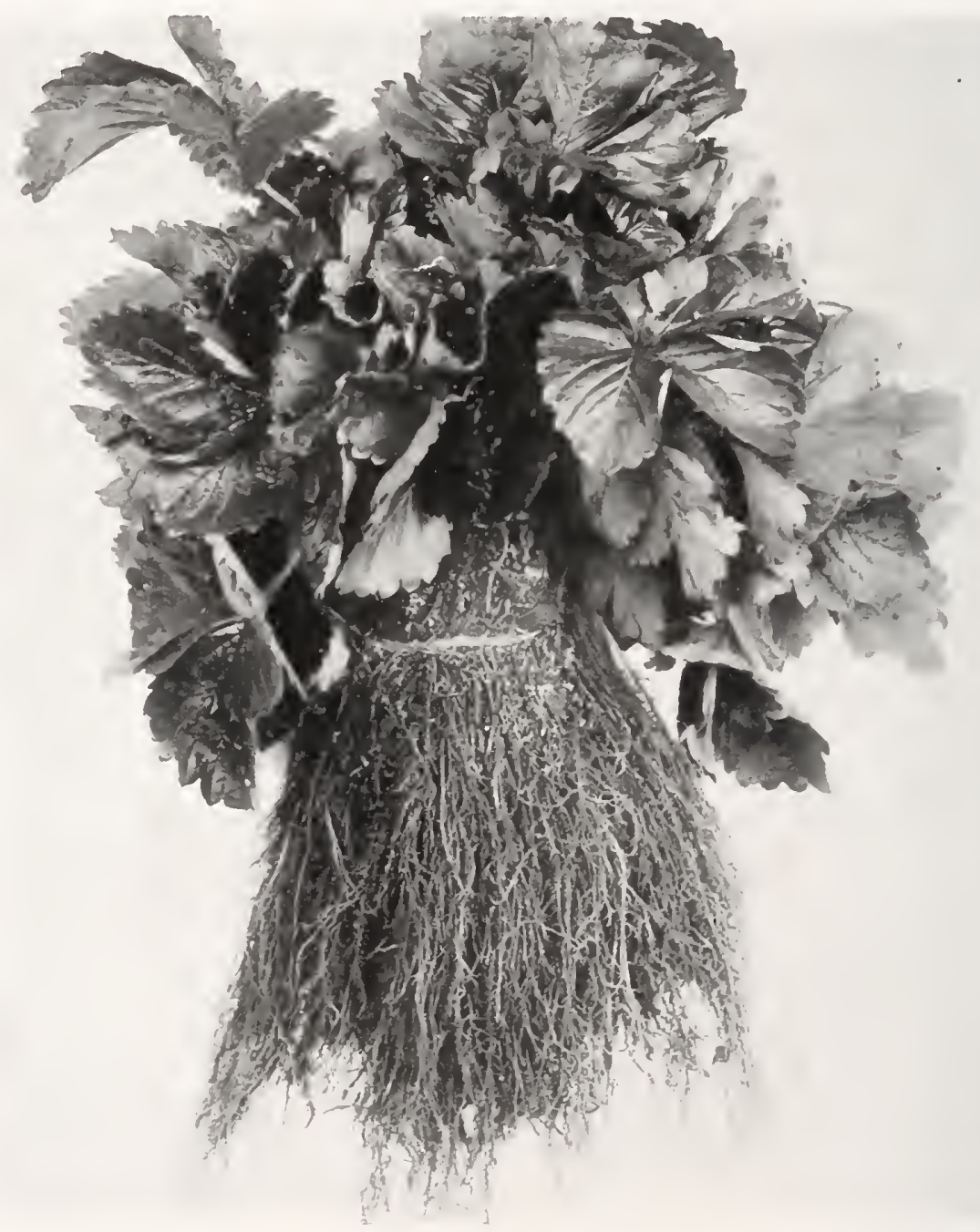

\section{Carman Nursery Company}

THE LAWRENCE NURSERIES Lawrence, Kansas 


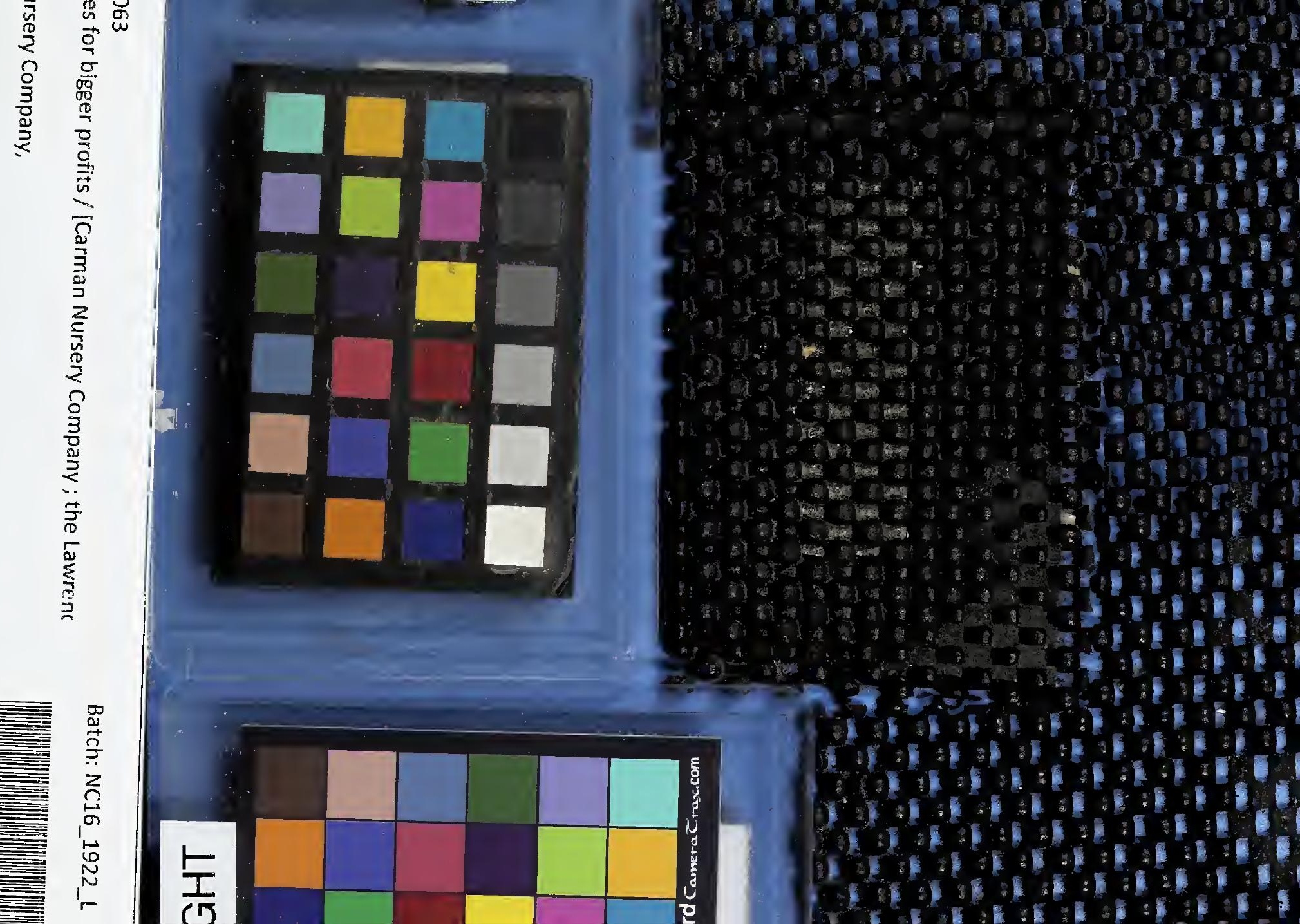


